\title{
CHILD SAFETY ON VARIOUS BICYCLE-MOUNTED SEATS DURING VEHICLE IMPACT
}

\author{
Mariusz PTAK*, Johannes WILHELM, Marek SAWICKI, Eugeniusz RUSIŃSKI \\ Faculty of Mechanical Engineering, Wroclaw University of Science and Technology, Poland
}

Received 28 July 2018; revised 15 November 2018; accepted 20 November 2018;

first published online 18 March 2019

\begin{abstract}
This research addresses an important gap in the state of the art by investigating the safety of vulnerable road users - children transported on bicycle seats. The article focuses on three forms of bicycle-mounted child seats and their kinematics during an accident scenario involving a motor vehicle. The front, rear-frame and rear-rack mounted child seat mounting configurations were considered in this study. The research covers the impact of a sports sedan vehicle against a bicycle equipped with the child seat. The assessment of the child safety was done through numerical simulations by coupling the codes of MADYMO and LS-DYNA. The after-impact kinematics for various baby carriers is presented with the emphasis on child's head and neck injuries. The results were compared to the full-scale test available in the literature. The findings prove a low protection level for the child provided by the bicycle carriers in all considered cases. The study is further devoted to directions of increasing child safety in this means of transportation.
\end{abstract}

Keywords: bicycle child seat, bicycle baby carrier, cyclist, accident reconstruction, road traffic safety, passive safety device, LS-DYNA, MADYMO.

\section{Introduction}

Transporting children on bicycles by using dedicated baby seats has recently become popular in European Union (Küster 2015; Biernat et al. 2018). The background for choosing this type of urban transport might be given also in environmental and ecological topics. Is it also a form of transport, which enables parenting children in their young ages, when their physical abilities to ride a bicycle on their own are not high enough. The appropriate carriers for front and rear mounting on the bicycle are therefore widely available on the market and easily attachable to common bicycles. The technical restrictions for the application are mainly given by a specific minimum diameter of the seat post tube and appropriate general bike geometry. This includes a proper contact surface of the tyres to the ground to ensure force handling while riding. Hence, the baby carriers shall not be mounted on race bicycles. The increased occurrence of baby carriers on bicycles might be connected to the fact, that using a bicycle becomes nowadays even a statement for a healthy lifestyle. Also the acceptance to wear passive safety devices as safety helmets seems to rise significantly (Ptak et al. 2018). Thereby, it is generally accepted, that wearing a proper fitted safety helmet reduces the risk of severe head injuries in the case of an accident involving head impact (Fernandes et al. 2018b, 2018c; Monea et al. 2014; Ratajczak et al. 2016).

However, detailed information about occupant safety concerning child seats mounted to bicycles is very limited (Miyamoto, Inoue 2010) or partially even missing completely. As one example out of a few only, Miyamoto and Inoue (2010) treated in the hospital numerous children, who were subjected to a fall out of a baby carrier. Further, they performed full-scale drop tests to increase the understanding about risk of baby carriers and the importance of wearing a helmet. Thus, the comparison is done to data from the hospital's emergency unit. Generally, literature points on a lack of stored and baby carrier-related data, which was reported to Police or other institutions. This includes for an accident the lack of knowledge about the specific bicycle type or mounted additional equipment, especially the used type and mounting version of the baby carrier (Lindman et al. 2015; Oxley et al. 2016). In a consequence, in these examples and statistics only a focus on the observed injuries of the child is possible, while there is a lack of understanding of the dynamic behaviour of the baby carrier in an accident scenario. To overcome this, Zander et al. (2013) performed a full-scale test of

${ }^{*}$ Corresponding author. E-mail: mariusz.ptak@pwr.edu.pl 
five different bicycles with two different baby carriers. In all cases, the bicycle with adjusted dummies was impacted by an older compact car. They concluded, that the cyclist is about to impact to the vehicle's front more rearward than a pedestrian. Furthermore, they underlined the positive effects of passive safety devices in an accident scenario (Zander et al. 2013). In a third source of information, customer testing needs to be addressed. Nevertheless, in respect to possible accident scenarios, the inevitable information is lacking and reduced only to general advices such as to use seat belts properly or making the child to wear a safety helmet. In addition, the increase in use of carriers has raised questions regarding their safety in Australia (Raftery et al. 2016).

The authors of this publication are motivated consequently to enrich the research about bicycle baby carriers crashworthiness. Through presenting the results of several simulations considering an accident configuration for various child seats, the authors will assess the safety aspects of the child in the particular scenario. To the authors' knowledge, this research is one of the first published attempts of advanced numerical simulation of a real-world car-to-bicycle impact scenario by considering child transportation on a bicycle.

\section{Methodology}

In a first step, the authors analysed available forms of bicycle baby carriers. Concerning their position on the bicycle, the carriers can be divided into the groups of front- and rear-mounted versions (Figure 1). Front-mounted baby carriers are operational up to a child mass of approximately $15 \mathrm{~kg}$. Thus, they are recommended for younger kids. Their mounting structure is attached to the top tube or front part of the bicycle frame. In some versions, also a bar is apparent, which has to be installed between a seat post and headset tube of the bicycle. It serves as a mounting bar for the carrier itself. On the other hand, rear-mounted versions use regularly a bracket, which is installed to the seat post tube, and supports the carrier by a rod structure. In a variant of the rear-mounted version, the baby carrier is also fixed to the luggage rack. This additional support helps to reduce the undesirable swings of the device.

The special attention has to be given to the used seatbelt systems. Rear-mounted versions are popular and representing an entry-level solution in this sector. They are offered mainly with a 3-point seatbelt system, which has been recently criticised for not securing a child during a lateral impact (Ptak 2019). In opposite to this, common

a)

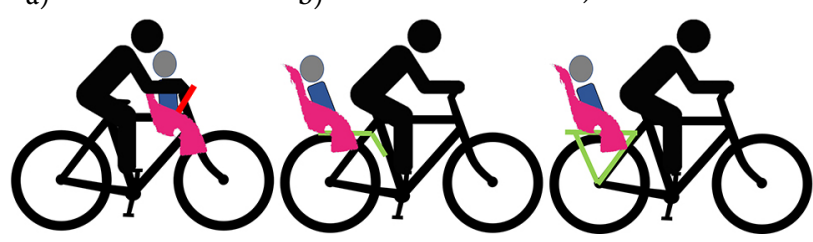

Figure 1. Child seat mounting configurations: $\mathrm{a}-$ front mounted; b - rear-frame mounted; c - rear-rack mounted forms of front-mounted versions offer a seatbelt system, which additionally restrict a child in the area of legs and hip. These four- or five-point seatbelt solutions secure the child better in a defined seating position within the given structural geometry of the seat, even in rough driving conditions. The seat belts in the carriers are made of polyamide fibres and are different to the seat belts used in modern cars. It is different also in a technical aspect, as neither a belt roller nor a retractor can be found on baby carrier seat belt systems. The seat belt itself was modelled out of quad SHELL elements and orientated on common seat belt creation and routing routines out of literature (Madymo TASS 2013). An elastic material model with a Young's modulus of $E=607.5 \mathrm{MPa}$ was applied basing on the carried out experimental tests. Additionally, in terms of restrictions, the feature of an installed bar or plate in front of the seat needs to be mentioned. It keeps the child away from the steering bar and bicycle stem. Nevertheless, these features are not a standard.

In this research, the most common bicycle baby seats are chosen: a front-mounted carrier and two rear-mounted baby carriers, while one of them is supported additionally by the fixation to the luggage rack. Consequently, the computer models needed to be created. The physical objects were measured using 3D scanning technologies. The used laser scanner is $808 \mathrm{~nm}$ wavelength unit, which measures the distance using the interferometry technology. A dedicated software such as Cyclon by Leica combines each of scanned cloud of points in spherical coordinate system to single common i.e. Cartesian coordinate system. The result of the measurement is a combined cloud of points from all scans, which is the basis for reproducing the geometry of the baby seats as Computer-Aided Design (CAD) models, depicted in Figure 2. The resulting pointto-point scanning tolerance was approximately $1 \mathrm{~mm}$.

a)

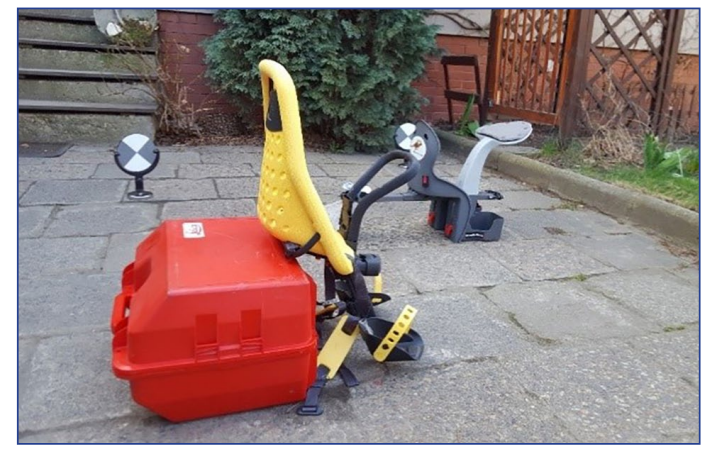

b)

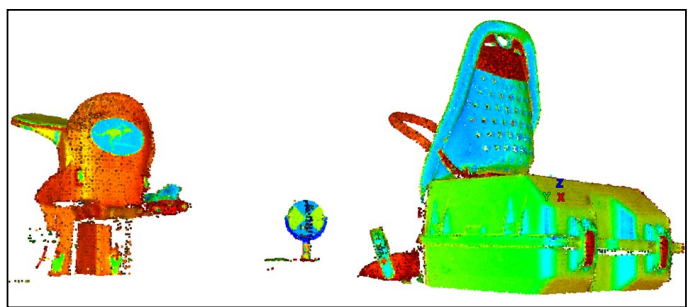

Figure 2. 3D laser scanning: a - two various designs of frontmounted baby carriers; $b$ - reflectivity colour spectrum applied onto cloud of points 
The clouds of points of several scans were aligned to each other by using dedicated markers in order to gain accurate geometrical data of the overall scanned object. The geometrical CAD model are further converted into a discrete (Computer-Aided Engineering - CAE) models, which were processed in LS-DYNA finite-element code (Rusiński et al. 2000). This procedure was repeated for all the baby carriers, which were used within these simulations. In a result, the authors ensure the representation of common carriers with their specific geometries. In order to gain knowledge about the real material properties, the authors cut several specimens out of one baby carrier. The material, which is specified as polypropylene without fibre-reinforcement, underwent then the tensile tests. The averaged value for the calculated Young's modulus is $1.11 \mathrm{GPa}$. In the literature, Young's modulus varies for polypropylene in the range of $0.89 \ldots 1.55 \mathrm{GPa}$ (Cambridge University Engineering Department 2003). The Poisson's ratio was assigned to $v=0.4$. The material model MAT_ELASTIC in LS-DYNA was used for the baby carrier within the simulations.

Unlike the baby carriers, the bicycle was modelled in MADYMO environment as multibody. Multibodies represent the geometry simplified, yet include crucial information as e.g. inertia, material and mass (Ptak 2019). The chosen bicycle is a mountain bike with the front suspension included. It was chosen due to the seat post tube diameter, which is necessary to mount the baby carrier and the proper rims/tyre combination for handling forces while driving. What is more, the mountain bike was recognized by the authors as a popular bicycle type, which is often used in combination with a baby carrier. The geometry of the MADYMO bicycle was created with particular effort to reflect the geometry and moments of inertia of a real-world bicycle (Ptak, Konarzewski 2015).

In addition, the included dummies are from the MADYMO code. The 50th percentile male Hybrid IIIdummy used in this research is the most popular implemented test dummy in terms of performance evaluation of automotive restraint and safety devices. The child was consciously chosen due to its mass of $11 \mathrm{~kg}$, which is representing a child fitting in all used forms of baby carriers (Madymo TASS 2013). Overall, the MADYMO dummies are applied in numerous cases due to their calculator robustness and bio-fidelity, ensuring reduced computational effort (Nie, Yang 2014; Ptak et al. 2018).

In this investigation, the bicycle will be impacted by a sports sedan vehicle (Figure 3). The vehicle model was created by the authors for the reconstruction of a pedestrian fatal accident and it is represented as FE-code in LS-DYNA. The full procedure of the vehicle validation is presented in research by Fernandes et al. (2018a) and the further validation was presented by Fernandes et al. (2018b) to the main court, as it was a part of accident reconstruction for the forensic analysis. The selected frontal design of Audi TT can be seen as a generic vehicle model. This choice is also supported by literature, as accidents

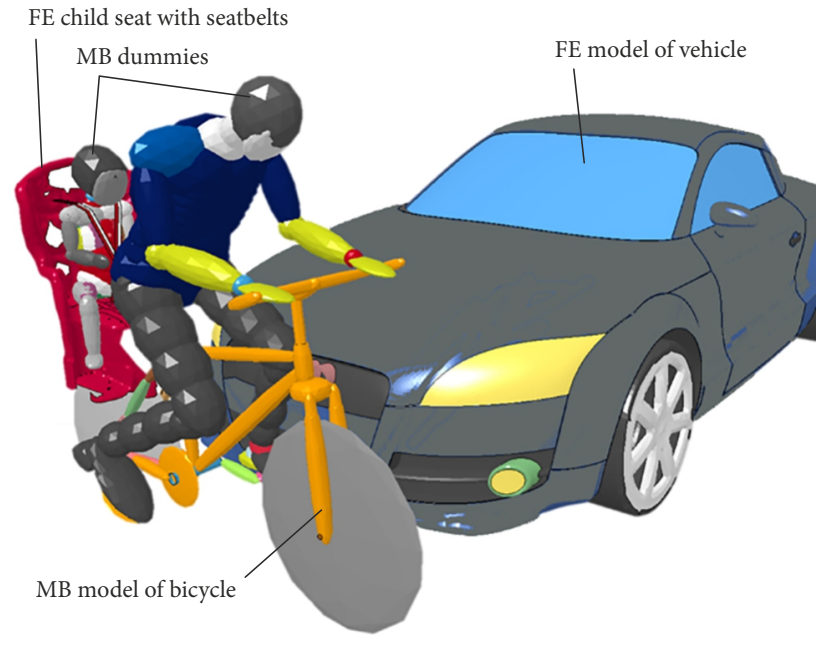

Figure 3. Initial setup for the rear-mounted baby carrier without luggage rack support - the type of numerical models is indicated for coupled simulations

with pedestrians or cyclists are more often reported for older vehicles (Lindman et al. 2015). The only comparable example of a baby carrier accident in literature was found in a full-scale test performed by the Federal Highway Research Institute (Bundesanstalt für Straßenwesen - BASt) in Germany (Zander et al. 2013). The BASt used the Volkswagen Golf Mk5 with comparable front-end geometrical parameters as the Audi TT. As comparison of the gathered simulative results could be done only to this full-scale test, the presented research is not about to focus at this stage on the influence of differing vehicle front-end geometry or other.

The LS-DYNA and MADYMO codes were coupled at this stage with each other. In a consecutive step, the connection between baby carrier with the bicycle itself and calculator to the FE-model of the vehicle is realised by the use of COUPLINGs, CONTACT and RESTRAINTs. The motivation was to gain especially knowledge about the kinematics of the child during an accident. Furthermore, the specific movement of the child corresponding to the used general type of baby carrier shall be observed. The results of several simulations will help to reveal the protection level of the carriers as passive safety device in the crash situation.

In order to compare the results, the impact scenario is set up as follows. Zander et al. (2013) presented a fullscale impact test, in which bicycles with rear-mounted baby carrier were impacted by an angle of $90^{\circ}$ directly to the side by a sedan vehicle traveling at $40 \mathrm{~km} / \mathrm{h}$, while the tandem was standing still. This bicycle configuration is also supported by Lindman et al. (2015) as it is the most common accident configuration between cars and cyclists.

The bicycle was covered completely by the front-end of the vehicle. Even if the standing still bicycle is unrealistic for real-world cases, the results may help to state about the authors' simulative results. In terms of the impacting direction of the full-scale test, most of impact scenarios in literature are described in this way (Lindman et al. 2015). 
To exclude influences of the kinematics out of initial leg position or general cyclist posture in the moment of first contact between bicycle and vehicle, the dummies posture is equal in all simulation cases (Bourdet et al. 2014).

\section{Results}

The cyclist motion after the impact by a vehicle with sedan front-end is described and compared often to the kinematics of pedestrians (Jurecki et al. 2017; King 2018). The kinematics of these two groups of vulnerable road users differs mainly in a more rearward head impact location for cyclists (Zander et al. 2013). This might be connected to a higher position of the cyclist's Centre Of Gravity (COG) compared to a pedestrian (Crocetta et al. 2015). Apart from this, a cyclist that is not using special equipment such as click-in pedals, is usually able to loosen from his vehicle after the impact. Hence, the kinematical outcome can be comparable to an impacted pedestrian. In opposite to this, as initially mentioned, details about child kinematics are rare or not available in current literature (Oxley et al. 2016). The gathered results shall be divided in the general categories as follows:

- bicycle motion;

- cyclist motion and head impacts;

- carrier behaviour, in order to state about the overall safety situation of the child in this crash scenario.

\subsection{Bicycle motion}

In all cases, the bicycle was lifted clearly from the ground after the impact. Comparing Figures $4 \mathrm{~b}$ and $4 \mathrm{c}$ with Figure $4 \mathrm{a}$ it can be seen, that the bicycle with the front-mounted baby carrier is not only lifted, but thrown more to the front. The adult's head impact occurs later than the child's head. The part of the bicycle, where the baby carrier was mounted, stays closer to the vehicle's front-end. The frontmounted carrier is located higher from the ground com- pared to the rear-mounted version. This rises the height of the CoG of the tandem. The authors observed that frontmounted versions were lifted more up in the air during the accident. This results for the child in a significant increased dropping height. Due to the seatbelt system, the child is still attached to the bicycle. Thus, vertical velocity and acceleration components might be increased for the child regarding the possible second impact to the ground. In a consequence, higher values of Head Injury Criterion (HIC) will be obtained (Raslavičius et al. 2017). It points on the possibility of suffering severe injuries of head and brain. These values are highlighted in the next sub-paragraph. Additionally, the bicycle, which is connected to the child body through the seatbelts, will influence the overall inertia during this second impact to the ground in terms of head and neck injuries. In opposite to this, the adult loosens in all cases from the tandem.

For the cases of the rear-mounted version, also the lifting of the bicycle is recognized, but the bicycle is driven more by the front of the vehicle instead of throwing the tandem to its forward driving direction.

\subsection{Cyclist motion and head impact}

During the analysis of the bicycle kinematics, it was already recognized, that the adult was able to loosen from the tandem during the impact. Furthermore, the bicycle motion behaviour is very similar in all three cases. Recapitulating Figure 4, the initially described kinematics of a cyclist is here visible, which is generally comparable to the behaviour of a pedestrian (Peng et al. 2012). The adult is wrapped over the bonnet of the vehicle and impacts in all three cases with a Wrap Around Distance (WAD) of approximately $2200 \mathrm{~mm}$ to the vehicle's windshield (Kubiak et al. 2018). The calculated WAD is here comparable to the results of the full-scale test performed by Zander et al. (2013) for rear-mounted baby carriers. The child's behaviour here is dependent on the carrier's motion, as it a)

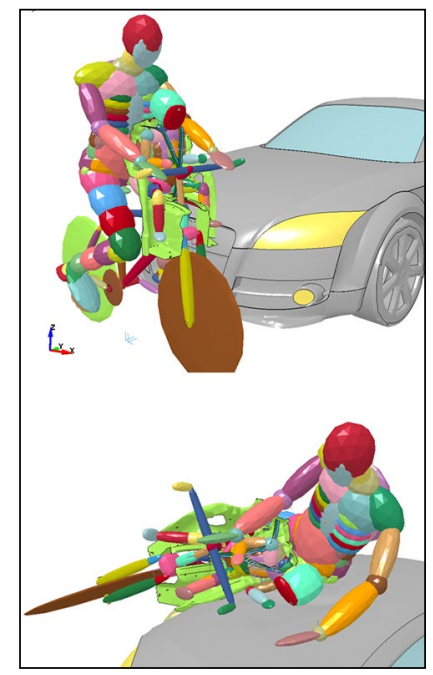

b)

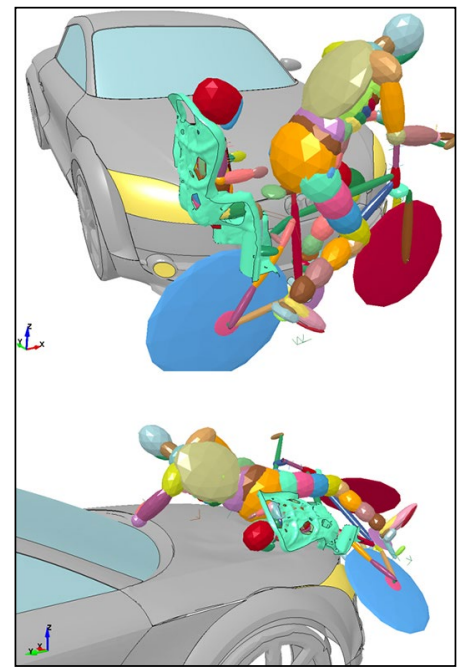

c)

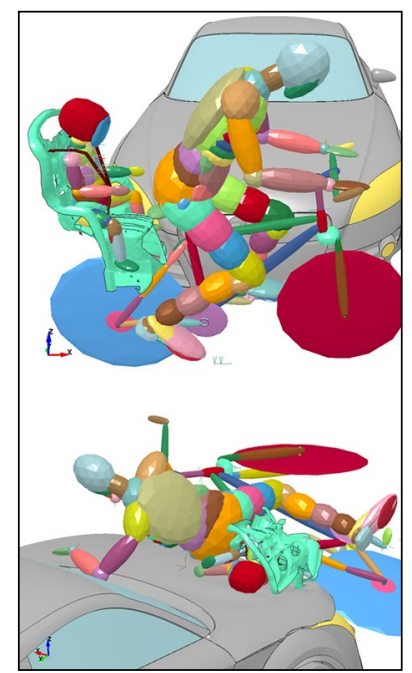

Figure 4. Tandem initial set-up (upper row) and after impact kinematics of dummies in 100 ms (lower row) for: a - front carrier; b - rear-mounted carrier; c - rear-mounted carrier with additional support (the vehicle impacting at $40 \mathrm{~km} / \mathrm{h}$ ) 
is belted to it. The situations of the child and its motion in the moment of the first head impact are given in Figure 4. In all cases, the head impact occurs directly without any damping effects of interacting extremities. The mounting definition of the front-mounted carrier representing a bar underneath the seat supports the carrier in its initial position. In addition, the belting situation of the child's legs and hips enables the child to stay in the geometry of the seat. Nonetheless, due to the low backrest of a front-mounted baby carrier and lacking side structures in general for all versions, head and extremities are impacting freely to the bonnet. Thereby, the high acceleration values are leading to high HIC, which is the standardised maximum integral value of the head acceleration for the corresponding time interval of $36 \mathrm{~ms}$ (MDVFS 2008). Generally, HIC bases on the resultant linear acceleration $a$ in time domain $t$ and is formulated by the Equation:

$$
H I C=\sup _{t_{1}, t_{2}}\left(\left(\frac{1}{t_{2}-t_{1}} \cdot \int_{t_{1}}^{t_{2}} a(t) d t\right)^{2.5} \cdot\left(t_{2}-t_{1}\right)\right),
$$

where: $a$ - resultant acceleration of the centre of gravity of the head $\left[\mathrm{m} / \mathrm{s}^{2}\right] ; t$ - time domain $[\mathrm{s}] ; t_{1}$ and $t_{2}$ are the moments [s] during an impact for which the HIC is the maximum value.

HIC finds a threshold for possible severe, but not lifethreatening brain injuries at 1000 (Fernandes 2017). All calculated values are given in Table. It points on the low protection level of the carrier structure in terms of side impacts and underlines the necessity of wearing adequate passive safety devices as safety helmets to reduce the risk of injuries. The additional significant lateral bending of the neck in the case of the front-mounted baby carrier can be clearly seen in Figure 4 and might indicate on further possible trauma occurrence (Milne et al. 2013).

Concentrating on the moment of the first head impact, the impact occurs for the adult always at around $160 \mathrm{~ms}$ after the start of the simulation. The start is set approximately to the initial contact between the vehicle and bicycle tandem. The child's head impact is observed for the front-carrier around $20 \mathrm{~ms}$ earlier than for the rearmounted versions. Interestingly in this scenario, the adult rider seems to be driven more by the bicycle, as his head reaches a magnitude in velocity of $8 \mathrm{~m} / \mathrm{s}$ in $Z$ direction (orientation of the gravity vector) in comparison to 4.7 $\mathrm{m} / \mathrm{s}$ by involving rear-mounted baby carriers. The more restricted space in the front of the adult is preventing the adult from loosen freely from the tandem and seems to play a role for the increased HIC(36) of the adult.

Summarising the overall kinematics of the child and adult dummy models, a direct cranial impact is highly likely for both of the cyclists. Due to the free movement of both bodies, only interfering extremities (a hand or shoulder) can be estimated as possible interactors with damping properties.

\subsection{Carrier behaviour}

In addition, the baby carrier itself influences the characteristics of body motion and initial head impact. The front-mounted version does not show major geometrical details to handle higher side forces, which might be even introduced by the inertia of the child. Here, the 4 or even 5 -point seatbelt systems play an important role as they secure the child in its seating position. Based on examined group of bicycle child seats, only one had an inner piping structure. Even though this structural stiffener is used, the baby carrier is made of polypropylene. Thus, the low backrest allows significant deformation of the carrier in its upper construction. In a result, the baby is moved by the bicycle and the carrier, but is able to interact with all objects around freely. This could include also the steering bar, stem, any other in this area intruding objects or even the body of the adult. In a consequence, this could lead not only to further neck injuries for the child, but also to injuries to the adult's torso.

The second groups of carriers, which are mounted to the rear or luggage rack of the bicycle, behave in general similar to rear-mounted carrier without additional support. It was observed during the simulations, that the upper backrest structure of the seat was more deformed, when the carrier was using additional support by the luggage rack. The rear-mounted carrier without additional support is only attached to the bicycle frame by a bracket. The mounting structure out of rods was bended and partially rotated by the acting forces during the impact around this installation point. In a result, the child's body is allowed to impact in this configuration more frontally to the bonnet. The baby seat side geometry played in both cases no relevant role in order to carry loads or prevent from impacts. Thus, the crashworthiness of the carrier in side-impact situations is neglectable and underlines its general role as a seat only and not as a passive safety device.

Table. Calculated characteristic head impact data

\begin{tabular}{|c|c|c|c|c|c|c|c|}
\hline \multirow{2}{*}{ Configuration } & \multirow{2}{*}{$\begin{array}{l}\mathrm{HIC}(36) \\
\text { for child }\end{array}$} & \multicolumn{2}{|c|}{ Head impact at [ms] } & \multicolumn{2}{|c|}{$\begin{array}{l}\text { Magnitude neck torque } \\
\text { (flexion/extension) }[\mathrm{N} \cdot \mathrm{m}]\end{array}$} & \multicolumn{2}{|c|}{ WAD $[\mathrm{mm}]$} \\
\hline & & child & adult & child & adult & child & adult \\
\hline Front-mounted baby carrier & 1846 & 90 & 160 & 14 & 103 & 1400 & 2200 \\
\hline Rear-mounted baby carrier & 1699 & 105 & 160 & 28 & 64 & 1550 & 2200 \\
\hline $\begin{array}{l}\text { Rear-mounted baby carrier } \\
\text { with additional support }\end{array}$ & 1191 & 110 & 160 & 14 & 54 & 1700 & 2200 \\
\hline
\end{tabular}




\subsection{Rear-end crash scenario}

Despite the fact that the impact to the side of the bicycle are reported as the most common configuration (Simms, Wood 2009), a full-scale test by ADAC (2008) focused on classic rear-end crash involving bicycles with different forms of baby carriers. The test involved the sedan vehicle impacting the bicycle from the back - imitating a failed passing situation (Figure 5).

The significant lift of bicycle's front wheel and an intrusion of the rear wheel into the vehicle's front-end was characteristic for this full-scale impact scenario. The fullscale test inspired the authors to reconstruct the case by the suitable simulation, in which the still-standing bicycle was hit by the vehicle with a velocity of $25 \mathrm{~km} / \mathrm{h}$. Thereby, simulations for front- and rear-mounted baby carriers were performed. For both versions, the characteristic lifting of the front-wheel was reported. As already stated, mounting a baby carrier to the bicycle changes the overall $\mathrm{CoG}$ of the bicycle. The effect of changing the CoG leads to significant variations in the overall bicycle motion, as the authors recognized. In the case of a rear-mounted carrier, the baby rolls over the bonnet, leading to the possibility of head impacts in the occipital region. This might be happening against the backrest, as far as the seatbelts are fastened properly and the length of the backrest is in accordance to the child height (Baranowski et al. 2015). This raises the necessity of keeping the child consequently in its seating position over the whole impact scenario. By using front-mounted carriers also the front wheel lifting is documented. As the baby carrier does not touch the bonnet but as a significant mass concentration is more distanced from this impact or contact point. In consequence, the distance of the transported child from the ground is rising. Furthermore, a missing long backrest leads to intensive bending of the child's neck shortly after the initial impact. The resultant forces are projecting and throwing the bicycle for- and upward leading to significant rotation of the whole bicycle. The increased dropping height has to be seen as a circumstance, leading to increased vertical dropping velocity and consequently also to possible higher impact energy in a head impact to the ground.

Concentrating on the adult, the dummy loosens from the bicycle in all cases, as the dummy is not using click inpedals or any similar restraint systems. The position of the baby carrier influences thereby the motion of the adult. For rear-mounted seats, the adult impact to the child is likely, as it was observed also in the photographs from the full-scale test. A corresponding injury possibility by this action has to be considered additionally for the child. As this restraint is missing in the case of a front-mounted baby carrier, the adult is recognized to be impacting directly to the vehicle. Recapitulating the side-impact scenarios, a first contact between adult and vehicle was recognized between the cyclist's leg and the vehicle's bumper. The authors observed in the rear-end crash scenario a first impact with the posterior to the bonnet followed by a head impact to the windshield. The WAD is out of this circumstance higher than for side impact configurations due to the higher first impact position on the top of the bonnet.

\section{Conclusions}

In this study, the special concern was put to the description of the post-impact kinematics of three different forms of bicycle baby carriers. This publication is one of the first numerical approaches of simulating a real-world impact

a)

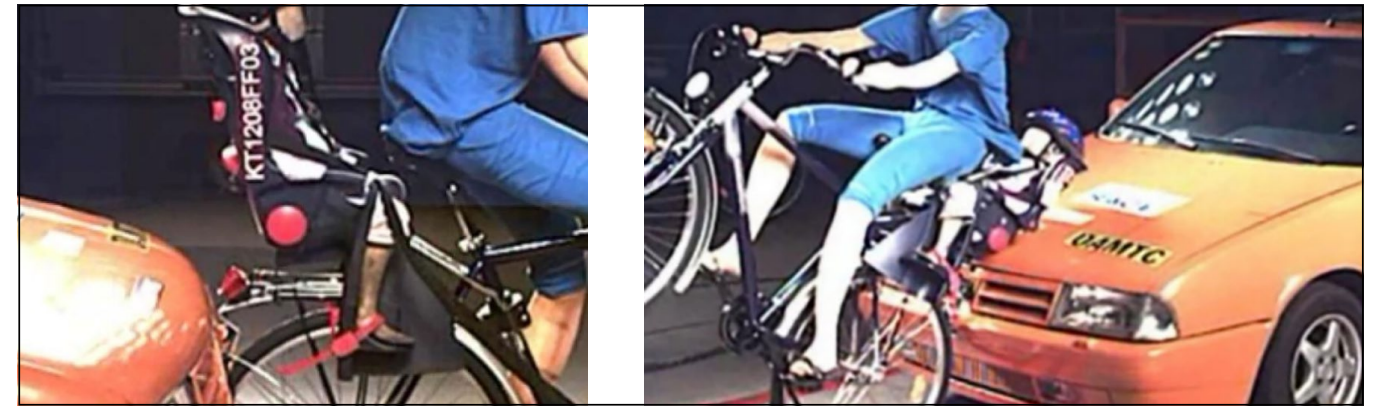

b)

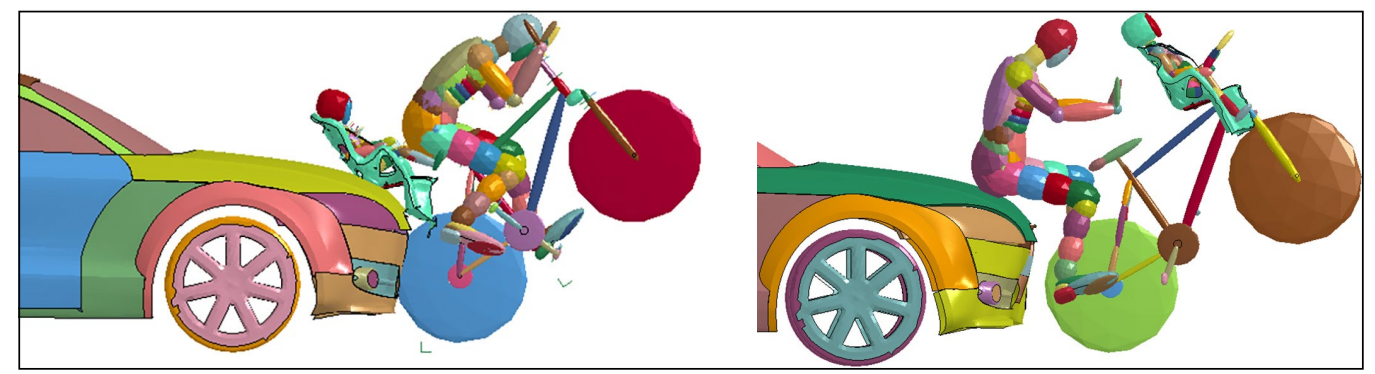

Figure 5. Rear-end crash: a - full-scale test performed by ADAC (2008); b - authors' original simulations for rear and front mounted child seat 
scenario of a bicycle-to-car collision with the consideration of child safety on various bicycle-mounted seats. The safety issues of transported children on bicycles have been inadequately presented in the current literature in terms of both kinematics and in injury outcome. Using a FE vehicle model coupled with a multibody bicycle, dummies and various baby carriers, the authors numerically simulated the most common impact scenarios. Thus, this research advances the current state-of-the-art. The results of the simulations proved a complex motion of the bicycle users and authors focused on the safety consequences for the seated child. The after-impact kinematics for various baby carriers was presented with the emphasis on child's head and neck injuries. As transporting young children by use of bicycle baby seats in urban areas increases, this novel study gains high importance. Even if the number of simulations is limited in this approach, the conclusions shall be formulated as follows:

- among the considered cases, the bicycle baby carrier does not prevent the child from impacting objects or lowering the collision severity;

- children seated in front-mounted baby carriers are impacted earlier comparing to rear-mounted baby carriers; a projection and throwing of the bicycle with front-mounted carrier was observed, leading to significant dropping height;

- front-seated children show higher HIC(36) values and less WAD than children in rear-mounted baby carriers, which is connected to an earlier head-tobonnet impact;

- advanced forms of seat belt systems, e.g. four- or five-point systems are crucial to secure the child's seating position and increase the child overall safety;

- in accordance to the presented study, the front pads with foam liner seem to be intended for keeping the child away from the steering bar or stem; however, these devices are not standard equipment of frontmounted carriers;

- a second head impact after the head impact to the bonnet or windshield is for both cyclists highly probable.

It can be stated, that the post-impact behaviour of the bicycle and especially the kinematics of the child is strongly dependent on the used type of baby carrier. Adult cyclists, on the presented form of a bicycle tandem, seem to behave such as regular cyclists in crash conditions. Yet, in specific cases, their motion is influenced by the presence of the child and its seat. The child's behaviour is contradictory, as the young passenger is kept by the belting system. Thus, it must be noted that child after-impact behaviour neither represents the kinematics of a cyclist nor a pedestrian. Nonetheless, the presented approach of simulating accident scenario involving bicycles with baby carriers points, by its preliminary character, on the necessity to intense the research. The expected increase in the number of cyclists on European roads makes study important to highlight major safety issues when transporting child passengers. The benefit has to be seen in possible enhancements of these popular devices in terms of passive safety. This original research proves that there is a need to intense the research in the field of child transport on bicycles - thus, the authors are aware of the need of combining the numerical approach with full-scale test as follow-up studies.

\section{Acknowledgements}

This research was financially supported by the Dean of the Faculty of Mechanical Engineering, Wroclaw University of Science and Technology (Poland) prof. Tomasz Nowakowski.

Moreover, the publication was developed as part of project LIDER/8/0051/L-8/16/NCBR/2017 funded by the National Centre for Research and Development (Poland).

\section{References}

ADAC. 2008. ADAC-Test zum Kindertransport auf Fahrrädern. Allgemeiner Deutscher Automobil-Club (ADAC). Available from Internet: https://rp-online.de/leben/auto/ratgeber/adactest-zum-kindertransport-auf-fahrraedern_bid-11565323 (in German).

Baranowski, P.; Damaziak, K.; Malachowski, J.; Mazurkiewicz, L.; Muszyński, A. 2015. A child seat numerical model validation in the static and dynamic work conditions, Archives of Civil and Mechanical Engineering 15(2): 361-375. https://doi.org/10.1016/j.acme.2014.07.001

Biernat, E.; Buchholtz, S.; Bartkiewicz, P. 2018. Motivations and barriers to bicycle commuting: lessons from Poland, Transportation Research Part F: Traffic Psychology and Behaviour 55: 492-502. http://doi.org/10.1016/j.trf.2018.03.024

Bourdet, N.; Deck, C.; Serre, T.; Perrin, C.; Llari, M.; Willinger, R. 2014. In-depth real-world bicycle accident reconstructions, International Journal of Crashworthiness 19(3): 222-232. https://doi.org/10.1080/13588265.2013.805293

Cambridge University Engineering Department. 2003. Materials Data Book. Cambridge, UK. 41 p.

Crocetta, G.; Piantini, S.; Pierini, M.; Simms, C. 2015. The influence of vehicle front-end design on pedestrian ground impact, Accident Analysis \& Prevention 79: 56-69. https://doi.org/10.1016/j.aap.2015.03.009

Fernandes, F. A. O. 2017. Biomechanical Analysis of Helmeted Head Impacts: Novel Materials and Geometries: PhD Thesis. University of Aveiro, Portugal. Available from Internet: https://ria.ua.pt/handle/10773/21227

Fernandes, F. A. O., Alves de Sousa, R. J., Ptak, M. 2018a. Application of numerical methods for accident reconstruction and forensic analysis, in Head Injury Simulation in Road Traffic Accidents, 59-98. http://doi.org/10.1007/978-3-319-89926-8_4

Fernandes, F. A. O.; Alves de Sousa, R. J.; Ptak, M. 2018b. Finite element head modelling and head injury predictors, in Head Injury Simulation in Road Traffic Accidents, 1-23. https://doi.org/10.1007/978-3-319-89926-8_1

Fernandes, F. A. O.; Alves de Sousa, R. J.; Ptak, M. 2018c. Head Injury Simulation in Road Traffic Accidents. Springer. 98 p. https://doi.org/10.1007/978-3-319-89926-8

Jurecki, R.; Stańczyk, T.; Jaśkiewicz, M. 2017. Driver's reaction time in a simulated, complex road incident, Transport 32(1): 44-54. https://doi.org/10.3846/16484142.2014.913535

King, A. I. 2018. Car-Pedestrian Impact, in The Biomechanics of Impact Injury: Biomechanical Response, Mechanisms of Injury, Human Tolerance and Simulation, 569-595.

https://doi.org/10.1007/978-3-319-49792-1_17 
Kubiak, P.; Mierzejewska, P.; Szosland, A. 2018. A precise method of vehicle velocity determination based on measurements of car body deformation - non-linear method for the 'Luxury' vehicle class, International Journal of Crashworthiness 23(1): 100-107. https://doi.org/10.1080/13588265.2017.1328763

Küster, F. 2015. An EU Roadmap for Cycling. European Cyclists' Federation (ECF). Available from Internet: https://ecf.com/groups/eu-roadmap-cycling

Lindman, M.; Jonsson, S.; Jakobsson, L.; Karlsson, T.; Gustafson, D.; Fredriksson, A. 2015. Cyclists interacting with passenger cars; a study of real world crashes, in 2015 IRCOBI Conference Proceedings, 9-11 September 2015, Lyon, France, 1-12. Available from Internet: http://www.ircobi.org/wordpress/downloads/irc15/pdf_files/10.pdf

Madymo TASS. 2013. Release Notes Manual, Release 7.5. Available from Internet: https://tass.plm.automation.siemens.com/madymo

MDVFS. 2008. Crash Analysis Criteria 2.1.1. Messdatenverarbeitung Fahrzeugsicherheit (MDVFS). 156 p. Available from Internet:

http://mdvfs.org/download/crash-analysis-criteria-2-1-1

Milne, G.; Deck, C.; Bourdet, N.; Alline, Q.; Gallego, A.; Carreira, R.; Willinger, R. 2013. Assessment of bicyclist head injury risk under tangential impact conditions, in 2013 IRCOBI Conference Proceedings, 11-13 September 2013, Gothenburg, Sweden, 735-746. Available from Internet: http://www.ircobi. org/wordpress/downloads/irc13/pdf_files/90.pdf

Miyamoto, S.; Inoue, S. 2010. Reality and risk of contact-type head injuries related to bicycle-mounted child seats, Journal of Safety Research 41(6): 501-505. https://doi.org/10.1016/j.jsr.2010.10.004

Monea, A. G.; Van der Perre, G.; Baeck, K.; Delye, H.; Verschueren, P.; Forausebergher, E.; Van Lierde, C.; Verpoest, I.; Vander Sloten, J.; Goffin, J.; Depreitere, B. 2014. The relation between mechanical impact parameters and most frequent bicycle related head injuries, Journal of the Mechanical Behavior of Biomedical Materials 33: 3-15.

https://doi.org/10.1016/j.jmbbm.2013.06.011

Nie, J.; Yang, J. 2014. A study of bicyclist kinematics and injuries based on reconstruction of passenger car-bicycle accident in China, Accident Analysis \& Prevention 71: 50-59. https://doi.org/10.1016/j.aap.2014.04.021

Oxley, J.; O’Hern, S.; Raftery, S.; Woolley, J. 2016. How safe are children when transported by bicycle?, Traffic Injury Prevention 17: 163-167. https://doi.org/10.1080/15389588.2016.1199866

Peng, Y.; Chen, Y.; Yang, J.; Otte, D.; Willinger, R. 2012. A study of pedestrian and bicyclist exposure to head injury in passenger car collisions based on accident data and simulations, Safety Science 50(9): 1749-1759. https://doi.org/10.1016/j.ssci.2012.03.005

Ptak, M. 2019. Pedestrian safety: a new method to assess pedestrian kinematics, Transport 34(1): 41-51. https://doi.org/10.3846/transport.2019.7081

Ptak, M.; Konarzewski, K. 2015. Numerical technologies for vulnerable road user safety enhancement, in A. Rocha, A. M. Correia, S. Costanzo, L. P. Reis (Eds.). New Contributions in Information Systems and Technologies 2: 355-364. https://doi.org/10.1007/978-3-319-16528-8_33

Ptak, M.; Wilhelm, J.; Saunders, N. 2018. Safety analysis of a bicycle-mounted child seat, in 2018 XI International ScienceTechnical Conference Automotive Safety, 18-20 April 2018, Casta, Slovakia, 1-6. https://doi.org/10.1109/AUTOSAFE.2018.8373316
Raftery, S. J.; Oxley, J.; Thompson, J.; Wundersitz, L. N. 2016. Transportation of Children with Bicycle Seats, Trailers, and other Carriers: Considerations for Safety. Report No CASR139. University of Adelaide, Australia. 54 p. Available from Internet: http://casr.adelaide.edu.au/publications/list/?id=1677

Raslavičius, L.; Bazaras, L.; Keršys, R. 2017. Accident reconstruction and assessment of cyclist's injuries sustained in car-tobicycle collision, Procedia Engineering 187: 562-569. https://doi.org/10.1016/j.proeng.2017.04.415

Ratajczak, M.; Sąsiadek, M.; Będziński, R. 2016. An analysis of the effect of impact loading on the destruction of vascular structures in the brain, Acta of Bioengineering and Biomechanics 18(3): 21-31. https://doi.org/10.5277/ABB-00552-2016-02

Rusiński, E.; Czmochowski, J.; Smolnicki, T. 2000. Zaawansowana metoda elementów skończonych w konstrukcjach nośnych. Oficyna wydawnicza Politechniki Wrocławskiej, 443 s. (in Polish).

Simms, C.; Wood, D. 2009. Pedestrian and Cyclist Impact: a Biomechanical Perspective. Springer. 230 p. https://doi.org/10.1007/978-90-481-2743-6

Zander, O.; Gehring, D.-U.; Leßmann, P. 2013. Improved safety of bicyclists in the event of a collision with motor vehicles and during single accidents, in 23rd International Technical Conference on the Enhanced Safety of Vehicles (ESV), 27-30 May 2013, Seoul, South Korea, 1-11. 